\title{
Basolateral Amygdala Is Involved in Modulating Consolidation of Memory for Classical Fear Conditioning
}

\author{
Almira Vazdarjanova and James L. McGaugh \\ Center for the Neurobiology of Learning and Memory and Department of Neurobiology and Behavior, University of \\ California, Irvine, California 92697-3800
}

Previous findings indicate that the basolateral amygdala complex of nuclei (BLC) is involved in modulating (i.e., enhancing or impairing) memory consolidation for aversive training such as inhibitory avoidance. The present study examined whether the BLC also modulates the consolidation of memory for classical fear conditioning in which a specific context is paired with footshock. Adult male rats with bilateral cannulae targeting the BLC were allowed, first, to habituate in a $Y$ maze that had differently shaped and textured arms. On the next day the rats were placed in one maze arm (shock arm), and they received four unsignaled footshocks. In Experiment 1, immediately after the training some rats received BLC inactivation with lidocaine (10 $\mu \mathrm{g} / 0.2 \mu \mathrm{l}$ per side), and control rats received buffered saline. In Experiment 2, rats received immediate post-training intraBLC infusions of the muscarinic receptor agonist oxotremorine (10 ng/0.2 $\mu$ l per side) or saline. On a $24 \mathrm{hr}$ retention test each rat was placed in a "safe" arm of the maze and allowed to access all maze arms. Lidocaine-treated rats had impaired memory for the classical fear conditioning when they were compared with the saline-treated controls: they spent less time freezing, entered the shock arm more readily and more often, and spent more time in it. In contrast, oxotremorine-treated rats had a stronger memory for the context-footshock association as assessed by all measures of memory. Thus, post-training treatments affecting BLC function modulate memory for Pavlovian contextual fear conditioning in a manner similar to that found with other types of training.

Key words: basolateral; amygdala; contextual; fear; conditioning; inhibitory; memory; consolidation; freezing; avoidance; post-training; temporary lesion; lidocaine; oxotremorine; modulation; enhancing
There is extensive evidence that the amygdaloid complex modulates memory consolidation by mediating the effects of adrenal stress hormones as well as drugs affecting opioid-peptidergic, GABAergic, and cholinergic systems (Liang et al., 1986; Brioni and McGaugh, 1988; McGaugh et al., 1988; Quirarte et al., 1997; Roozendaal and McGaugh, 1997a,b; Salinas et al., 1997; Cahill and McGaugh, 1998). Enhancement of memory for aversive experiences appears to involve muscarinic cholinergic receptor activation in the amygdala. Post-training intra-amygdala injections of muscarinic cholinergic agonists produce dose-dependent enhancement of memory for inhibitory avoidance (IA) and changes in reward magnitude (Introini-Collison et al., 1996; Salinas et al., 1997). Additionally, the blockade of amygdala muscarinic receptors prevents memory enhancement induced by systemic administration of muscarinic receptor agonists (Dalmaz et al., 1993; Introini-Collison et al., 1996).

Other recent evidence suggests that the modulation of memory consolidation by post-training treatments selectively involves the basolateral amygdala complex (BLC; defined as the lateral, basolateral/basal, and basomedial/accessory basal nuclei). Selective inactivation of the BLC with lidocaine (2-diethylamino- $\mathrm{N}-[2,6-$

Received Feb. 10, 1999; revised April 5, 1999; accepted May 10, 1999.

This research was supported by University of California, Irvine Regent's Fellowship and Schneiderman Graduate Fellowship (A.V.) and United States Public Health Service Grant MH12526 from the National Institute of Mental Health (J.L.M.). We thank Anguel Mantchev and Lila Avila for histological assistance. We also thank Dr. Benno Roozendaal, Dr. Georg Striedter, and Thane Plummer for helpful comments on a draft of this paper.

Correspondence should be addressed to Dr. Almira Vazdarjanova, 218 Bonney Laboratory, Center for the Neurobiology of Learning and Memory, University of California, Irvine, CA 92697-3800.

Copyright (C) 1999 Society for Neuroscience $\quad 0270-6474 / 99 / 196615-08 \$ 05.00 / 0$ dimethiphenyl]-acetamide) as well as blockade of the NMDA or glucocorticoid receptors in the BLC shortly after inhibitory avoidance training produces retrograde amnesia (Liang et al., 1994; Parent and McGaugh, 1994; Roozendaal and McGaugh, 1997b). Additionally, post-training blockade of the muscarinic cholinergic receptors in the BLC blocks the memory enhancement induced by systemically administered glucocorticoids (Power et al., 1998). Although much research investigating the role of the BLC in memory consolidation has used IA tasks, recent evidence indicates that the BLC also modulates the consolidation of memory for aversive, as well as appetitive, spatial/hippocampal-dependent training (Schroeder and Packard, 1998; Hatfield and McGaugh, 1999).

The BLC is also involved in the learning and retention of Pavlovian contextual fear conditioning (CFC), although the precise nature of the involvement remains controversial (Helmstetter and Bellgowan, 1994; Maren et al., 1996a,b; Muller et al., 1997; Maren, 1998; Vazdarjanova and McGaugh, 1998). Because the procedures used during CFC are similar to those in IA training (in both tasks the animals receive a footshock in a particular context), it may be expected that the BLC also modulates memory storage for CFC training. Maren et al. (1996b), however, report that post-training inactivation of the NMDA receptors in the BLC did not affect CFC memory as measured by freezing behavior. It has been suggested that the BLC differentially influences memory storage for CFC and IA training because these learning tasks differ in response contingency (Maren et al., 1996a; Maren, 1998). Indeed, in IA the footshock is contingent on the animals' response of entering the region of the apparatus where footshock is administered, whereas in CFC training there is no such con- 
tingency-rats are placed in a context in which they receive inescapable footshocks regardless of their behavior.

If the response contingency in IA is the critical element that determines the involvement of the BLC in modulating memory storage, then post-training treatments would not be expected to influence memory for CFC as they do for IA. The present experiments examined this issue further by investigating whether a general post-training BLC inactivation with lidocaine will impair, and stimulation of the cholinergic system of the BLC will enhance, memory for $\mathrm{CFC}$ as assessed by freezing as well as avoidance of the footshock-paired context.

\section{EXPERIMENT 1}

\section{Effects of post-training lidocaine infusions in the basolateral complex of the amygdala on memory for contextual fear conditioning}

In Experiment 1, rats were trained on a CFC task as described in Materials and Methods. Immediately after the training session, temporary bilateral inactivation of the BLC was induced by intraBLC infusions of a reversible sodium channel blocker, lidocaine. Because lidocaine has a well documented short-lived action on neuronal activity (Albert and Madryga, 1980; Martin, 1991; Welsh and Harvey, 1991; Boeijinga et al., 1993), any impairment in retention test performance $1 \mathrm{~d}$ later could be attributed to memory impairment resulting from the disruption of consolidation processes. The purpose of this experiment was to determine whether post-training inactivation of the BLC with lidocaine impairs memory for CFC.

\section{Materials and Methods}

Subjects. The subjects were 25 male Sprague Dawley rats (275-325 gm at the time of surgery) obtained from Charles River Breeding Laboratories (Boston, MA). They were housed individually in a light- and temperature-controlled vivarium $\left(22^{\circ} \mathrm{C}, 12 \mathrm{hr}\right.$ light/dark cycle; lights on at 7:00 A.M.). Food and water were available ad libitum.

Surgery. One week after their arrival, the rats were anesthetized with sodium pentobarbital $(55 \mathrm{mg} / \mathrm{kg}$, i.p.; Abbott Labs, Irving, TX) and injected with $0.2 \mathrm{ml}$ of atropine sulfate intraperitoneally (Phoenix Pharmaceuticals, St. Joseph, MO) to ensure unobstructed respiration. The head of each rat was affixed to a stereotaxic apparatus (Kopf Instruments, Tujunga, CA). After the skull was exposed, burr holes were drilled for the placement of bilateral cannulae (15 mm long, 23-gauge). The cannulae were lowered at coordinates $3.0 \mathrm{~mm}$ posterior to bregma and $5.0 \mathrm{~mm}$ lateral to the midline (nose bar at $-3.3 \mathrm{~mm}$ ) just dorsal to the BLC ( $-6.0 \mathrm{~mm}$ from the skull) and fixed in place with dental cement and two jewel screws attached to the skull. The scalp incision was closed with wound clips, and 15 -mm-long stylets were inserted in the cannulae to prevent clogging. The animals received $3 \mathrm{ml}$ of saline (subcutaneously) to prevent dehydration during recovery. The rats were placed in a temperature-controlled incubator, and their recovery was monitored. After recovery from anesthesia, they were returned to the home cages. All rats were handled every other day after the surgery. During the handling the stylets were removed, and 15 -mm-long sham needles were inserted into the cannulae to habituate the rats to the injection procedures (see below).

Behavioral apparatus. The CFC training and testing were performed in a Y maze. The three differently shaped and textured arms of the maze were $50 \mathrm{~cm}$ long and $18 \mathrm{~cm}$ deep, separated by $120^{\circ}$ and covered with transparent lids. The shock arm was constructed of stainless steel plates that were electrified by a shock generator (Lafayette Instruments, Lafayette, IN) controlled by a timer. The rats' behavior in the maze was observed in a mirror suspended $1.2 \mathrm{~m}$ above the maze on a side wall of the room.

Training procedure. All training and testing were performed between 12:00 and 5:00 P.M. The arms of the apparatus were cleaned thoroughly with $10 \%$ ethanol between subjects. On the habituation day (day 1) each rat was placed into one of the three arms and allowed to explore the entire maze for $8 \mathrm{~min}$. The time spent freezing (lack of any movement except for respiration) and the latency to each arm entry were recorded.
On the training day (day 2) the shock arm was blocked off from the rest of the maze by an opaque door. Each rat was placed in the shock arm and $60 \mathrm{sec}$ later received a series of 4 footshocks $(1 \mathrm{sec}, 1 \mathrm{~mA}$, spaced $60 \mathrm{sec}$ apart). The time spent freezing after each footshock was recorded. Then 1 min after the last footshock the rat was taken out of the maze, given a drug or control microinf usion in the BLC, and then returned to its cage. On the test day (day 3) each rat was placed into a maze arm in which shock was not delivered during the training. The latencies to each arm entry and the total time spent freezing during the 8 min retention test were recorded. All behavior was scored continuously by a trained experimenter "blind" to the treatment conditions.

Drugs and infusion procedures. Lidocaine (Sigma, St. Louis, MO) was dissolved in buffered saline, $\mathrm{pH} 7.4$, to a concentration of $50 \mu \mathrm{g} / \mu \mathrm{l}$. A fresh drug solution was prepared before each experiment and was kept in a light-proof vial to prevent inactivation. Bilateral post-training inf usions of saline or lidocaine were made through 30-gauge injection needles connected to a $10 \mu \mathrm{l}$ Hamilton syringe by polyethylene tubing. The needles protruded $2 \mathrm{~mm}$ beyond the tip of the cannulae to reach the BLC. A total of $10 \mu \mathrm{g}$ in volume of $0.2 \mu \mathrm{l}$ per side was inf used by an automated syringe pump (Sage Instruments, Boston, MA) over a period of $23 \mathrm{sec}$. The needles were retained in place for an additional $60 \mathrm{sec}$ to allow for diff usion within the BLC. The injection volume was chosen on the basis of previous findings reporting functional spread within the BLC, but not to the adjacent central nucleus (Parent and McGaugh, 1994; Roozendaal and McGaugh, 1997b; DaCunha et al., 1999), and that lesions of the BLC induced with 0.2 or $0.3 \mu \mathrm{l}$ of NMDA do not affect neurons in the central nucleus (Hatfield et al., 1996; Roozendaal and McGaugh, 1996; Roozendaal et al., 1996; Vazdarjanova and McGaugh, 1998).

Histology. At the completion of all behavioral testing, the rats were anesthetized deeply with an overdose of sodium pentobarbital (200 $\mathrm{mg} / \mathrm{kg}$, i.p.) and perfused intracardially with $0.9 \%$ saline, followed by $10 \%$ formaldehyde. The brains were removed and stored in $10 \%$ formaldehyde overnight and then transferred to $30 \%$ sucrose in $10 \%$ formaldehyde solution for at least $3 \mathrm{~d}$. The brains were sliced on a sliding microtome at $60 \mu \mathrm{m}$ sections. Every other section was mounted on a gelatin-coated slide and stained with cresyl violet. Two independent observers examined the slides under a light microscope to determine the placement of the injector tips.

Statistics. Only rats with injection needle tip placements within the BLC were included in the statistical analyses. The avoidance measures (initial latency to enter the shock arm, total time per arm, and total number of entries) were calculated from the latency to each arm entry measure. A repeated measure ANOVA with freezing after each footshock as a repeated measure and drug treatment as an independent variable assessed the freezing behavior during training. The effects of the drug treatments on memory during the test were analyzed with a one-way ANOVA, with drug treatment as an independent variable and freezing as a dependent variable, and a MANOVA, with treatment as an independent variable and all three avoidance measures as dependent variables. When the main effect of MANOVA was significant, the effect of a drug treatment on each individual avoidance measure was evaluated with a one-way ANOVA. Analysis with a paired Student's $t$ test examined the differences between pre- and post-training levels of the dependent variables (freezing and avoidance measures) for each drug treatment condition. A probability of $<0.05$ was considered significant.

\section{Results}

Figure $1 A$ illustrates the injection needle tip placements of rats in the saline $(n=11)$ and lidocaine groups $(n=9)$. A photomicrograph of a representative placement in the BLC is shown on Figure $1 B$. There were no differences on any behavioral measure between the rats assigned to the saline or lidocaine groups before the post-training injections. During the habituation period the rats did not show any freezing, nor did they avoid the arm in which they were to receive footshocks in (shock arm) (see Fig. 4B, C, dashed lines). Figure 2 shows that during training the rats displayed increasingly more freezing after each subsequent unsignaled footshock, $F_{(1,4)}=289.32 ; p<0.0001$. There was no difference in the level of freezing of the rats to be injected with lidocaine and those to be injected with saline after the training, as revealed by the lack of a main effect of treatment, $F_{(1,18)}=0.65$, not significant (NS). 

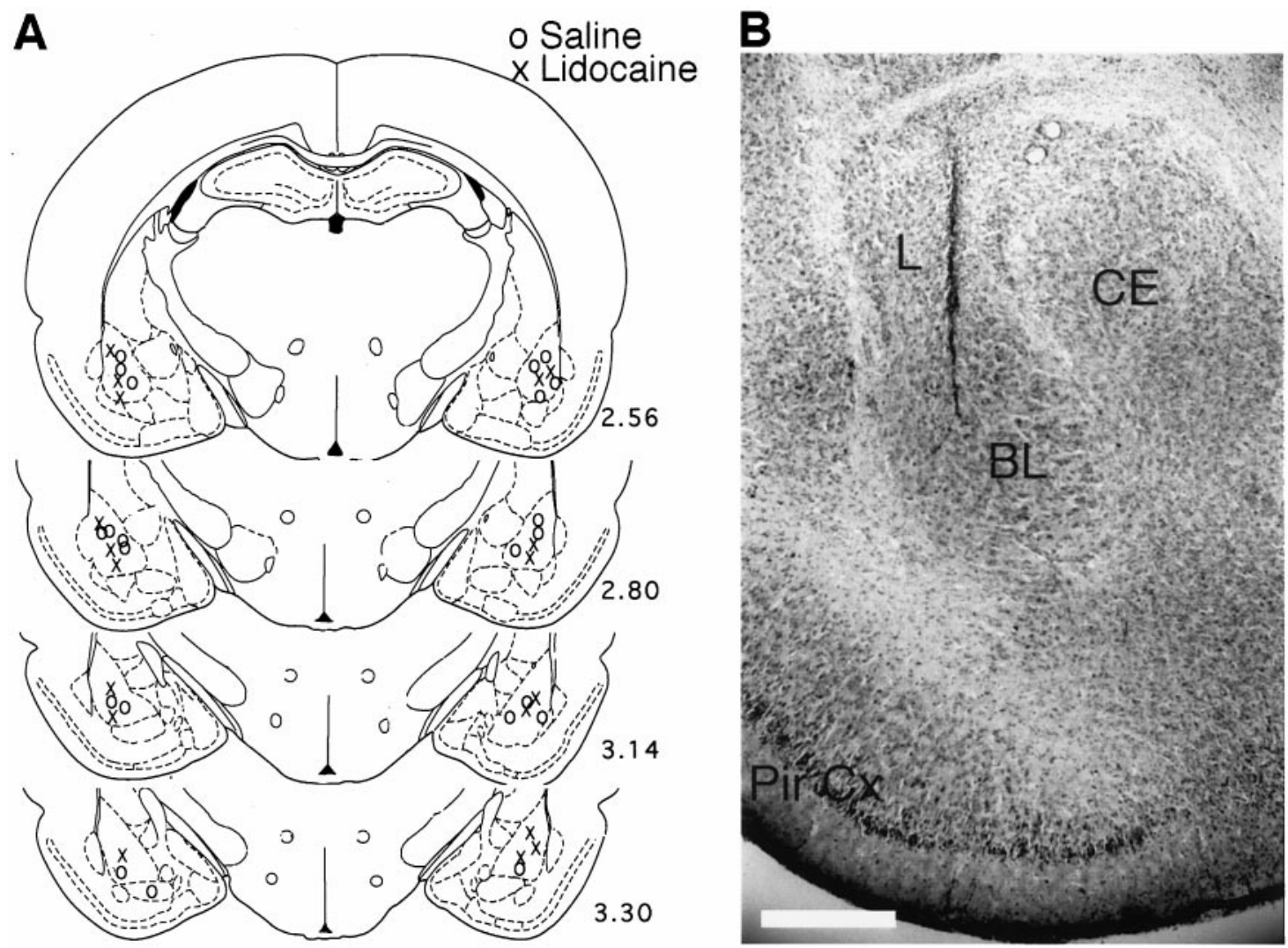

Figure 1. A, A schematic drawing illustrating the injector tip placements of saline-injected rats (circles) and lidocaine-injected rats (crosses). Numbers indicate relative position of the coronal sections in millimeters posterior to bregma (Paxinos and Watson, 1997). B, A microphotograph of a representative injector tip location. $L$, Lateral nucleus; $C E$, central nucleus; $B L$, basolateral/basal nucleus; Pir. $C x$, piriform cortex. Scale bar, 0.5 mm.

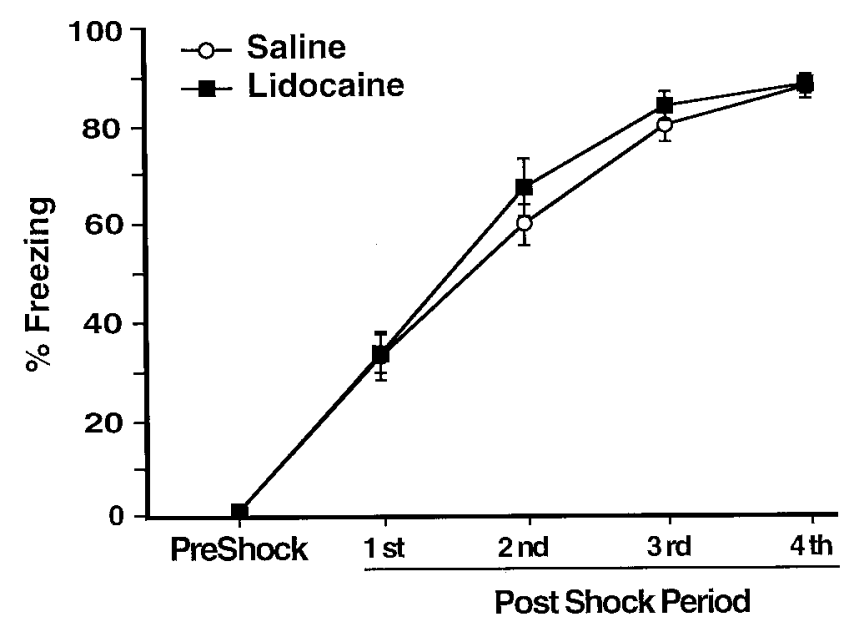

Figure 2. Mean percentage of time spent freezing $( \pm$ SEM) on day 2 before (PreShock) and during (1st-4th PostShock periods) training in rats that received inf usions of saline (open circles) or lidocaine ( filled squares) into the BLC after the training.

On the $24 \mathrm{hr}$ retention test rats that had received post-training infusions of lidocaine in the BLC were impaired on all memory measures when compared with the saline-injected controls. Figure 3 shows that the lidocaine-treated rats spent significantly less time freezing $\left[F_{(1,18)}=29.03 ; p<0.0001\right]$. As shown in Figure 4 and confirmed by a significant main effect of MANOVA [Wilks' lambda $\left.=0.37 ; F_{(3,16)}=9.10 ; p<0.001\right]$, the rats in the lidocaine

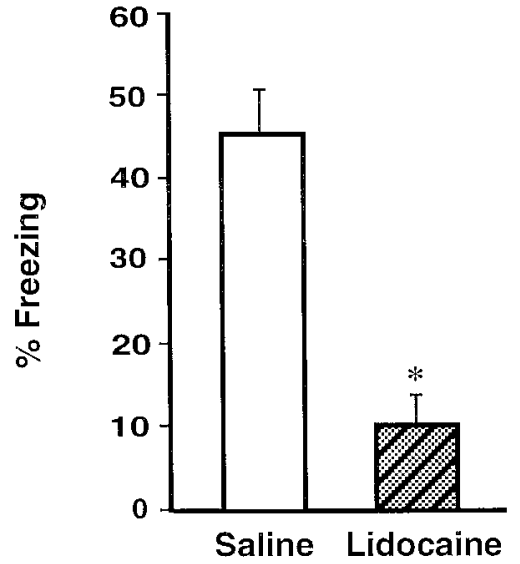

Figure 3. Impaired freezing of rats that had received post-training BLC inactivation. Shown is the mean time spent freezing $( \pm$ SEM) during the retention test on day 3 in saline-treated rats (open bar) and lidocainetreated rats (shaded bar). ${ }^{*} p<0.0001$ compared with the saline group.

group avoided the shock arm less than did the saline controls. Subsequent ANOVAs showed that rats in the lidocaine group entered the shock arm more quickly (Fig. $4 A$ ) $\left[F_{(1,18)}=27.65\right.$; $p<0.0001]$, more often (Fig. $4 B)\left[F_{(1,18)}=16.40 ; p<0.001\right]$, and spent more time (Fig. $4 C)\left[F_{(1,18)}=13.96 ; p<0.005\right]$ in the shock arm than did the rats in the saline group.

The findings of Experiment 1 indicate that memory for Pavlovian contextual fear conditioning, like that for IA, is impaired if the BLC is inactivated shortly after the training. These findings 
A

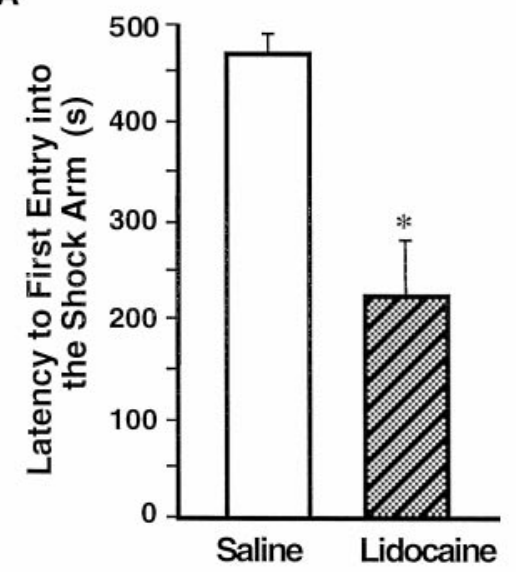

B

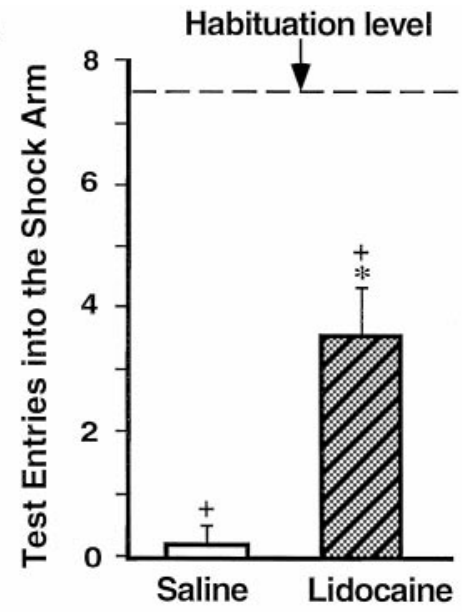

Figure 4. Impaired avoidance of rats that had received post-training BLC inactivation. $A$, Mean latencies, in seconds, to the first entry into the shock arm ( \pm SEM) during the retention test on day 3 for the saline group (open bar) and the lidocaine group (shaded bar). $B$, Mean number of entries in the shock arm $( \pm \mathrm{SEM})$ during the habituation period (dashed lines) and the retention test (bars). $C$, Mean percentage of time spent per arm during the habituation period on day 1 (dashed line) and the retention test on day 3 (bars; \pm SEM). ${ }^{*} p<0.005$ compared with the saline group; $*^{*} p<0.05$ compared with the respective group's percentage of time in either of the "safe" arms; +, $p<$ 0.005 compared with the habituation period.

C

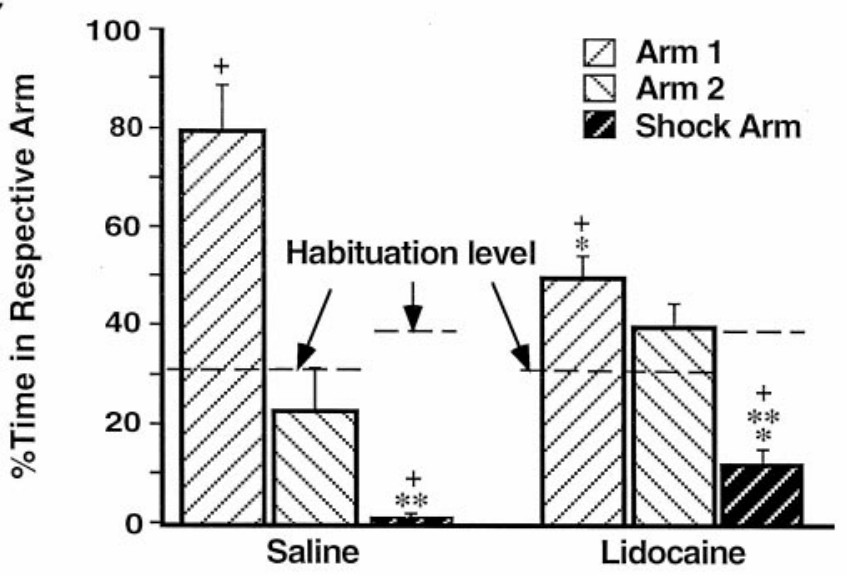

suggest that the involvement of the BLC in memory consolidation for fear-based learning does not depend on whether the feareliciting stimulus is contingent on an animal's response during the training.

\section{EXPERIMENT 2}

\section{Effects of post-training oxotremorine infusions in the basolateral complex of the amygdala on memory for contextual fear conditioning}

The finding of Experiment 1 indicating that post-training inactivation of the BLC impairs memory for CFC suggests that the BLC modulates memory strength for classical fear conditioning. A direct implication of this hypothesis is that post-training activation of the BLC should enhance CFC memory as it does IA memory. In Experiment 2 we examined whether post-training activation of the cholinergic muscarinic receptors in the BLC with oxotremorine enhances memory for CFC. Anatomical evidence indicates that one of the distinguishing characteristics of the basal nucleus of the amygdala is a high level of cholinergic activity evidenced by a dense acetylcholineesterase and choline acetyltransferase staining (de Olmos et al., 1985; Amaral et al., 1992). Furthermore, the excitability of BLC neurons is increased after muscarinic receptor activation (Washburn and Moises, 1992; Womble and Moises, 1992, 1993). Post-training intra-amygdala infusions of oxotremorine enhance memory for both IA and changes in reward magnitude (Introini-Collison et al., 1996; Salinas et al., 1997).

\section{Materials and Methods}

The methods and procedures were identical to those described in Experiment 1 except that the footshock intensity was $0.3 \mathrm{~mA}$ and the drug administered after the training was oxotremorine (as sesquifumarate salt; Sigma). A lower level of footshock (compared with $1.0 \mathrm{~mA}$ in Experiment 1) was used to avoid maximum levels of freezing and avoidance behavior in the control group, thus enabling the detection of any memory-enhancing effects of oxotremorine. The drug dose (10 ng/0.2 $\mu$ l per side) was determined on the basis of pilot experiments and published data (Salinas et al., 1997).

\section{Results}

Figure 5 shows the injection needle tip placements of rats in the saline $(n=12)$ and the oxotremorine groups $(n=13)$. On the habituation session the rats that were going to receive posttraining injections of oxotremorine or control solutions did not differ on any behavioral measure. The rats did not display any freezing, nor did they avoid the shock arm during the habituation session (see Fig. 8C). During the footshock training session the rats displayed increasingly more freezing after each subsequent unsignaled footshock presentation as confirmed by a significant effect of footshock, $F_{(1,4)}=204.94 ; p<0.0001$. There was no difference between the groups to be injected with saline or oxotremorine as revealed by the lack of a main effect of treatment, $F_{(1,23)}=0.05$, NS (Fig. 6). With the lower intensity footshock used in this experiment $(0.3 \mathrm{~mA})$, the rats displayed less freezing than did the rats in Experiment 1 (which used $1.0 \mathrm{~mA}$ footshock).

Rats given post-training intra-BLC infusions of oxotremorine displayed enhanced memory on the $24 \mathrm{hr}$ retention test as as- 


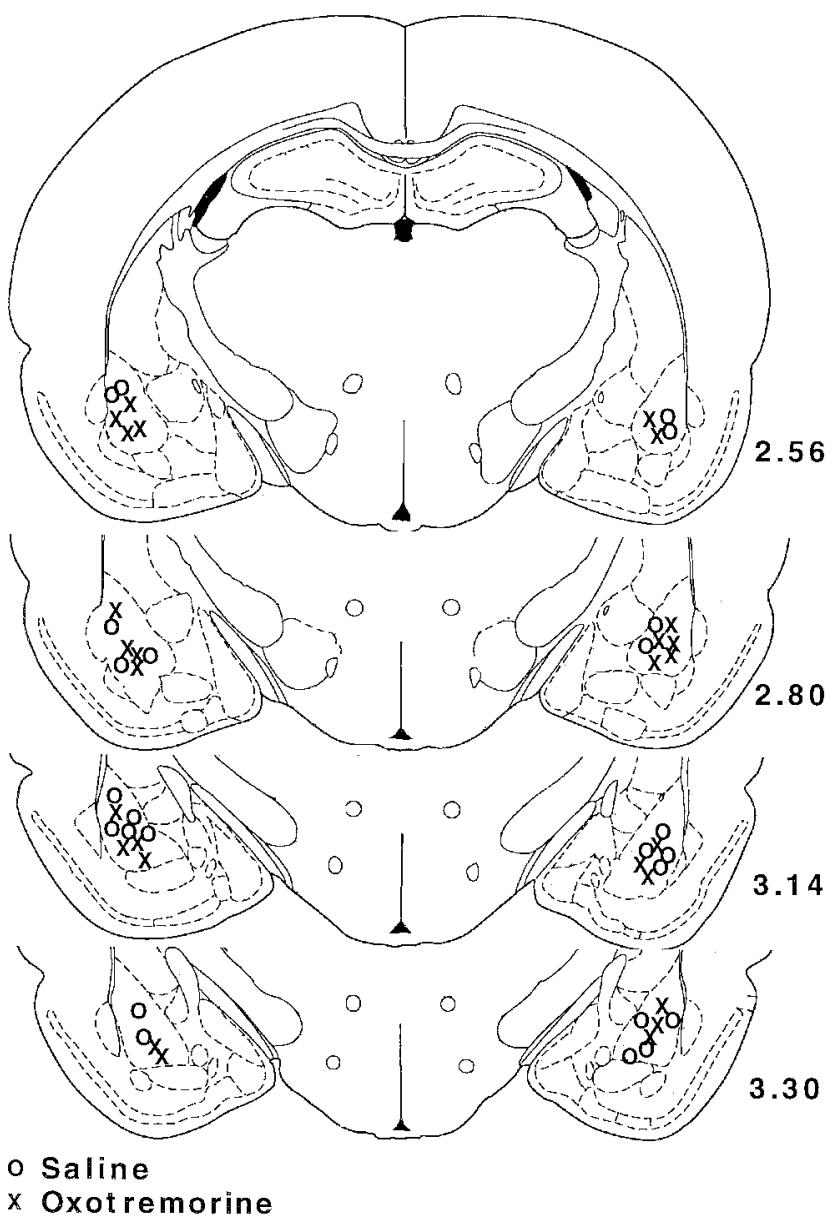

Figure 5. Injector tip placements for the subjects in the saline group (circles) and the subjects in the oxotremorine group (crosses). Numbers indicate relative position of the coronal sections in millimeters posterior to bregma (Paxinos and Watson, 1997).

sessed by all behavioral measures. Figure 7 shows that, in comparison with the saline-injected controls, the oxotremorinetreated rats spent significantly more time freezing $\left[F_{(1,23)}=12.46\right.$; $p<0.005]$. Additionally, as shown in Figure 8 and confirmed by a significant main effect of MANOVA [Wilks' lambda $=0.43$; $\left.F_{(3,21)}=9.36 ; p<0.0005\right]$, the rats in the oxotremorine group avoided the shock arm more than did the rats in the saline group. Subsequent one-way ANOVAs showed that the oxotremorinetreated rats entered the shock arm less readily $($ Fig. $8 A)\left[F_{(1,23)}=\right.$ 20.73; $p<0.0001]$, less often (Fig. $8 B)\left[F_{(1,23)}=19.55 ; p<\right.$ $0.0005]$, and spent less time (Fig. $8 C$ ) $\left[F_{(1,23)}=30.38 ; p<0.0001\right]$ in that arm than did the rats in the saline group. These findings support the hypothesis suggested by the results of Experiment 1 that the BLC modulates memory consolidation for CFC training. They further suggest that this memory modulation involves muscarinic cholinergic receptor activation in the BLC.

\section{DISCUSSION}

The findings of the present experiments are the first to show that the BLC is involved in modulating the consolidation of memory for Pavlovian CFC. Post-training inactivation of the BLC resulted in impaired memory for CFC (Experiment 1), and post-training muscarinic cholinergic receptor activation of the BLC enhanced CFC memory (Experiment 2). It should be noted that both

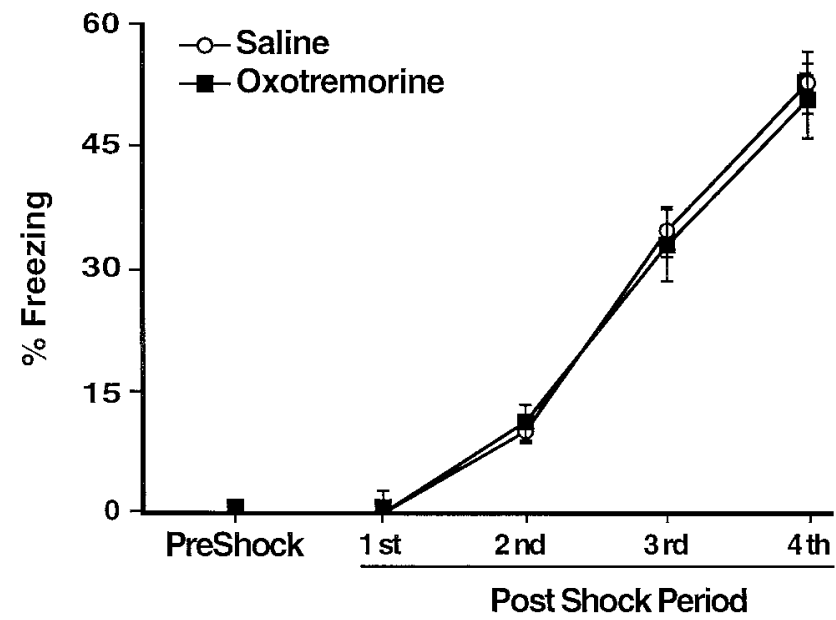

Figure 6. Mean percentage of time spent freezing $( \pm$ SEM) on day 2 before (PreShock) and during (1st-4th PostShock periods) training in rats that received infusions of saline (open circles) or oxotremorine (filled squares) into the BLC after the training.

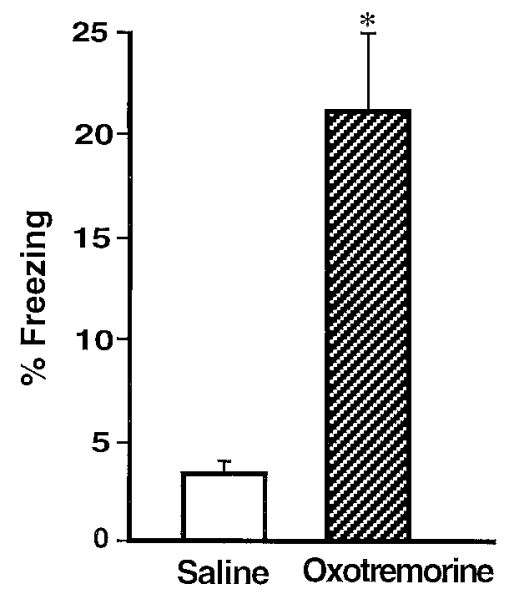

Figure 7. Enhanced freezing of rats that had received muscarinic cholinergic receptor activation of the BLC after the training. Shown is the mean time spent freezing $( \pm \mathrm{SEM})$ during the retention test on day 3 in rats that received post-training intra-BLC inf usions of saline (open bar) or oxotremorine (shaded bar). ${ }^{*} p<0.005$ compared with the saline group.

somatic and cognitive indices of fear memory were affected. In Experiment 1 BLC inactivation with lidocaine after the training resulted in a decreased level of both freezing and avoidance behaviors assessed at the retention test. The memory impairment most likely was attributable to inactivation of the cells in the BLC and not the fibers passing through this area, because post-training activation of the BLC muscarinic receptors with oxotremorine (Experiment 2) resulted in increased levels of both freezing and avoidance at the test. Although freezing may be viewed as causal to avoidance (if rats freeze, they also avoid the shock arm), the two behaviors are readily dissociable. In a recent study we showed that $24 \mathrm{hr}$ after CFC training (very similar to that used in the present experiments) BLC lesioned rats did not freeze, yet they avoided the shock arm (Vazdarjanova and McGaugh, 1998). As noted above, the lower retention scores of the control rats in Experiment 2 as compared with the control rats of Experiment 1 were attributable to the lower intensity of footshock that they received during the training.

Because the drug treatments were administered after the train- 
A

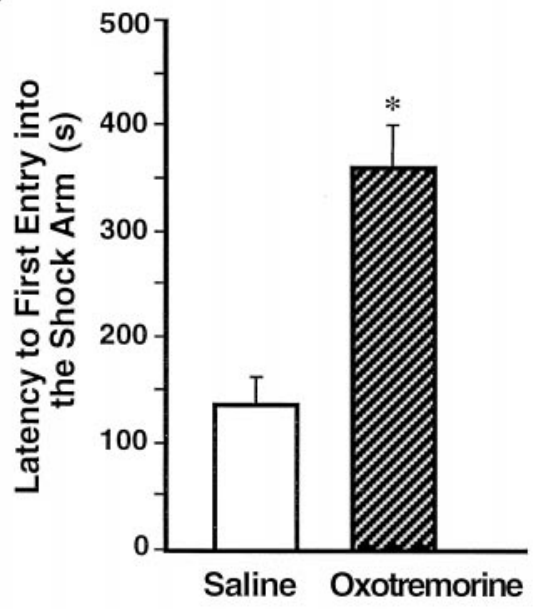

B

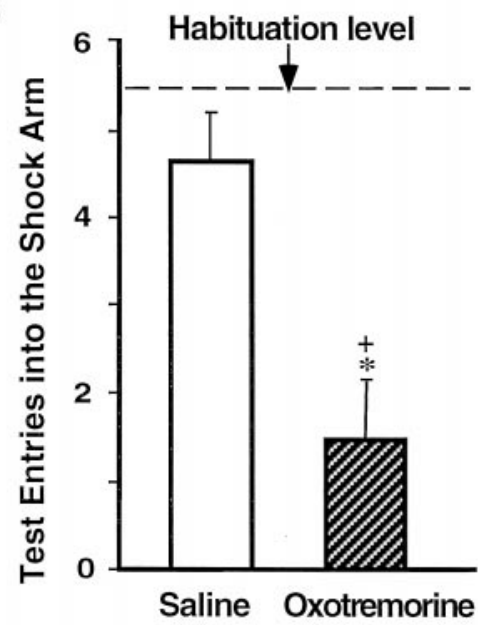

C

Figure 8. Enhanced avoidance of rats that had received muscarinic cholinergic receptor activation of the BLC after the training. $A$, Mean latencies, in seconds, to the first entry into the shock arm ( \pm SEM) during the retention test on day 3 for rats in the saline group (open bar) and the oxotremorine group (shaded bar). $B$, Mean number of entries in the shock arm $( \pm$ SEM) during the habituation period (dashed line) and the retention test (bars). $C$, Mean percentage of the time spent per arm during the habituation period on day 1 (dashed line) and the retention test on day 3 (bars; \pm SEM). ${ }^{*} p<$ 0.005 compared with the saline group; $* * p<0.01$ compared with the respective group's percentage of time in either of the "safe" arms;,$+ p<0.0001$ compared with the habituation period.

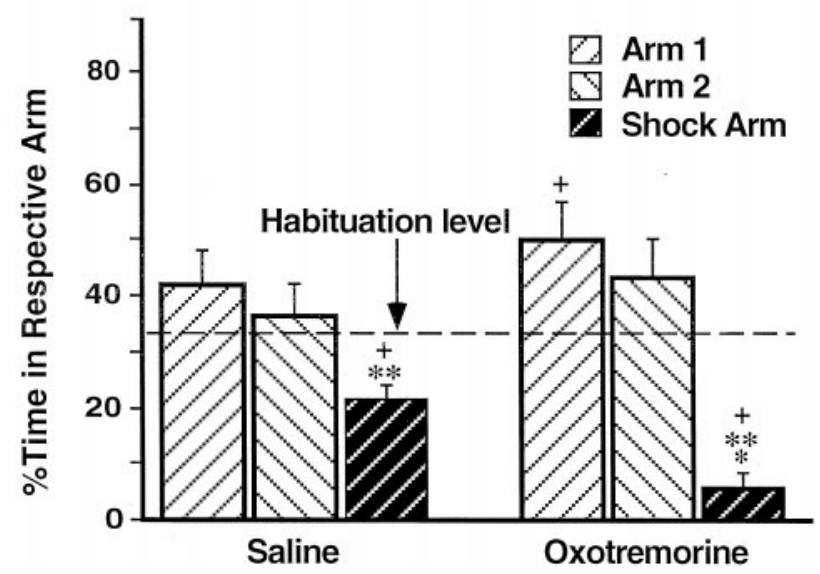

ing, the results do not reflect drug influences on acquisition (McGaugh, 1989). Additionally, the results were not likely attributable to the nonspecific drug effects on retention performance because both drugs have been reported previously to have no effect on performance $24 \mathrm{hr}$ after intra-amygdala injections (Parent and McGaugh, 1994; Salinas et al., 1997). Thus the present findings are consistent with a large number of studies examining the role of the BLC in memory consolidation in both rats and humans (Cahill and McGaugh, 1998; McGaugh et al., 1999). Excitotoxic BLC lesions either do not affect memory for IA (Tomaz et al., 1992; Roozendaal and McGaugh, 1996, 1997a) or, at most, attenuate such memory (Parent et al., 1995) or memory for CFC (Maren, 1998; Vazdarjanova and McGaugh, 1998). However, BLC lesions block glucocorticoid-induced modulation of memory for both IA and the spatial version of the Morris water maze task (Roozendaal and McGaugh, 1996; Roozendaal et al., 1996). Furthermore, post-training intra-BLC infusions of hormones and drugs are effective in either impairing or enhancing memory for training in these tasks. Post-training blockade of the sodium channels in the BLC (but not the adjacent central nucleus, CEA) attenuates memory for IA in a time-dependent manner (Lorenzini et al., 1994; Parent and McGaugh, 1994). Similarly, blockade of the high-affinity glucocorticoid receptors (GRs) in the BLC, but not the CEA, impairs memory for training in the spatial version of the Morris water maze task (Roozendaal and McGaugh, 1997b). Additionally, retention of IA is enhanced by post-training intra-BLC, but not intra-CEA, infusions of a GR agonist (Roozendaal and McGaugh, 1997b) or a benzodiazepine receptor antagonist (DaCunha et al., 1999). Last, post-training intra-amygdala NMDA receptor blockade (with the majority of the injection sites located within the BLC) impaired memory for IA, and post-training activation of the NMDA or noradrenergic receptors reversed the memory impairment produced from pretraining NMDA receptor blockade (Liang et al., 1993, 1994).

Maren et al., 1996b reported that immediate post-training blockade of the NMDA receptors in the BLC was ineffective in disrupting memory consolidation of $\mathrm{CFC}$ as measured by freezing. The discrepancy between these findings and the present results might be attributed to the fact that the subjects used in that experiment previously had undergone the same fear-conditioning procedure. Although the first training took place in a different context, it is possible that the initial highly aversive training masked the effect of a post-training memory impairment affecting the second training. It is also possible that the single dose used in that study was not optimal for influencing memory consolidation processes (although the same dose influenced acquisition). Thus, the present data and the majority of the cited studies support the view that the BLC has a role in modulating memory consolidation that is not task-specific.

Consistent with extensive previous findings, the present results (Experiment 2) stress the importance of muscarinic cholinergic receptor activation in the amygdala. Memory enhancement in- 
duced by post-training systemic administration of the muscarinic receptor agonist oxotremorine is blocked by a concurrent intraamygdala blockade of the muscarinic receptors with atropine (Dalmaz et al., 1993; Introini-Collison et al., 1996). Additionally, post-training blockade of the muscarinic receptors in the amygdala prevents the memory enhancement by a concurrent intraamygdala activation of $\beta$-noradrenergic receptors (IntroiniCollison et al., 1996). Furthermore, the results of Experiment 2 are consistent with recent findings from our laboratory suggesting that the BLC may be a locus of action of the muscarinic cholinergic activation in the amygdala (Power et al., 1998). This suggestion is supported further by evidence that the basal and accessory basal nuclei (along with the amygdala hippocampal area and the nucleus of the lateral olfactory tract) have the highest concentration of cholinergic activity among all amygdala nuclei (de Olmos et al., 1985; Amaral et al., 1992).

Because it has been suggested previously that the BLC stores memory for CFC training (Maren et al., 1996b; Maren, 1998), there are at least two possible explanations for the memoryenhancing effect of muscarinic receptor activation in the BLC observed in the present study. Such activation either may facilitate memory storage in the BLC itself or may contribute to BLC activation that, in turn, facilitates memory storage in other brain regions. Although the present data do not discriminate directly between these two possibilities, previous studies have shown that memory enhancement induced by systemic cholinergic activation is blocked by lesions of the stria terminalis, a major amygdala input-output pathway (Introini-Collison et al., 1989). Because systemic cholinergic activation has a primary locus of action in the amygdala (Dalmaz et al., 1993) and stria terminalis lesions do not have an effect on performance by themselves (Introini-Collison et al., 1989; Flood et al., 1995; Packard et al., 1996), these data strongly suggest that the amygdala cholinergic activation modulates memory storage in other brain regions (McGaugh et al., 1996).

Consistent with the latter hypothesis is extensive evidence that the excitability level of pyramidal neurons in the BLC is increased greatly after muscarinic cholinergic receptor activation or stimulation of cholinergic afferents to the BLC (Washburn and Moises, 1992; Womble and Moises, 1992, 1993). Such heightened excitability is reflected by an increased rate of neuronal firing and is caused by a reduction of one component of the afterhyperpolarization, namely reduction of the slow calcium-activated potassium current (Womble and Moises, 1993). Taken together with these electrophysiological data, the present results provide further support for the hypothesis that BLC affects memory consolidation by enhancing memory storage in other brain regions (McGaugh et al., 1996).

The second important finding of the present studies is that the BLC is involved in modulating the storage of memory for aversive tasks regardless of the response contingency during the training. The present findings based on Pavlovian CFC are highly comparable to those obtained previously in studies that used IA (Brioni et al., 1989; Jerusalinsky et al., 1992; Liang et al., 1993, 1994; Lorenzini et al., 1994; Parent and McGaugh, 1994; IntroiniCollison et al., 1996). As noted above, in IA the footshock delivery is contingent on a behavioral response whereas in Pavlovian CFC the shock delivery is not response-contingent. Because treatments affecting BLC functioning modulate memory for both tasks, it appears that the differences in response contingency are not critical in determining whether the BLC is involved in modulating memory storage. Furthermore, memory storage in both tasks is influenced by muscarinic cholinergic activation of the BLC.

In summary, the results of the present experiments indicate that the BLC is involved in modulating the storage of memory for Pavlovian contextual fear conditioning. Thus, these results are consistent with extensive evidence that the BLC is involved in modulating the storage of emotionally based memory in a wide variety of learning situations and that its involvement does not depend on the specific behavioral contingencies during training.

\section{REFERENCES}

Albert DJ, Madryga FJ (1980) An examination of the functionally effective spread of four microliters of slowly infused lidocaine. Behav Neural Biol 29:378-384.

Amaral DG, Price JL, Pitkanen A, Carmichael ST (1992) Anatomical organization of the primate amygdaloid complex. In: The amygdala: neurobiological aspects of emotion, memory, and mental dysfunction (Aggleton JP, ed), pp 1-66. New York: Wiley-Liss.

Boeijinga PH, Mulder AB, Pennartz CM, Manshanden I, Lopes da Silva FH (1993) Responses of the nucleus accumbens following fornix/ fimbria stimulation in the rat. Identification and long-term potentiation of mono- and polysynaptic pathways. Neuroscience 53:1049-1058.

Brioni JD, McGaugh JL (1988) Post-training administration of GABAergic antagonists enhances retention of aversively motivated tasks. Psychopharmacology (Berl) 96:505-510.

Brioni JD, Nagahara AH, McGaugh JL (1989) Involvement of the amygdala GABAergic system in the modulation of memory storage. Brain Res 487:105-112.

Cahill L, McGaugh JL (1998) Mechanisms of emotional arousal and lasting declarative memory. Trends Neurosci 21:294-299.

DaCunha C, Roozendaal B, Vazdarjanova A, McGaugh JL (1999) Microinfusions of flumazenil into the basolateral but not the central nucleus of the amygdala enhance memory consolidation in rats. Neurobiol Learn Mem, in press.

Dalmaz C, Introini-Collison IB, McGaugh JL (1993) Noradrenergic and cholinergic interactions in the amygdala and the modulation of memory storage. Behav Brain Res 58:167-174.

de Olmos J, Alheid GF, Beltramino CA (1985) Amygdala. In: The rat nervous system (Paxinos G, ed), pp 223-334. Sydney: Academic.

Flood JF, Merbaum MO, Morley JE (1995) The memory-enhancing effects of cholecystokinin octapeptide are dependent on an intact stria terminalis. Neurobiol Learn Mem 64:139-145.

Hatfield T, McGaugh JL (1999) Norepinephrine infused into the basolateral amygdala posttraining enhances retention in a spatial water maze task. Neurobiol Learn Mem 71:232-239.

Hatfield T, Han J-S, Conley M, Gallagher M, Holland P (1996) Neurotoxic lesions of basolateral, but not central, amygdala interfere with Pavlovian second-order conditioning and reinforcer devaluation effects. J Neurosci 16:5256-5265.

Helmstetter FJ, Bellgowan PS (1994) Effects of muscimol applied to the basolateral amygdala on acquisition and expression of contextual fear conditioning in rats. Behav Neurosci 108:1005-1009.

Introini-Collison IB, Arai Y, McGaugh JL (1989) Stria terminalis lesions attenuate the effects of posttraining oxotremorine and atropine on retention. Psychobiology 17:397-401.

Introini-Collison IB, Dalmaz C, McGaugh JL (1996) Amygdala betanoradrenergic influences on memory storage involve cholinergic activation. Neurobiol Learn Mem 65:57-64.

Jerusalinsky D, Ferreira MB, Walz R, Da Silva RC, Bianchin M, Ruschel AC, Zanatta MS, Medina JH, Izquierdo I (1992) Amnesia by posttraining infusion of glutamate receptor antagonists into the amygdala, hippocampus, and entorhinal cortex. Behav Neural Biol 58:76-80.

Liang KC, Juler RG, McGaugh JL (1986) Modulating effects of posttraining epinephrine on memory: involvement of the amygdala noradrenergic system. Brain Res 368:125-133.

Liang KC, Lin MH, Tyan YM (1993) Involvement of amygdala $N$-methyl-D-aspartate receptors in long-term retention of an inhibitory avoidance response in rats. Chin J Physiol 36:47-56.

Liang KC, Hon W, Davis M (1994) Pre- and posttraining infusion of $N$-methyl-D-aspartate receptor antagonists into the amygdala impair memory in an inhibitory avoidance task. Behav Neurosci 108:241-253.

Lorenzini A, Baldi E, Bucherelli C, Tassoni G (1994) Post-training nucleus basalis magnocellularis functional tetrodotoxin blockade effects 
on passive avoidance consolidation in the rat. Behav Brain Res 61:191-196.

Maren S (1998) Overtraining does not mitigate contextual fear conditioning deficits produced by neurotoxic lesions of the basolateral amygdala. J Neurosci 18:3088-3097.

Maren S, Aharonov G, Fanselow MS (1996a) Retrograde abolition of conditional fear after excitotoxic lesions in the basolateral amygdala of rats: absence of a temporal gradient. Behav Neurosci 110:718-726.

Maren S, Aharonov G, Stote DL, Fanselow MS (1996b) N-methyl-Daspartate receptors in the basolateral amygdala are required for both acquisition and expression of conditional fear in rats. Behav Neurosci 110:1365-1374.

Martin JH (1991) Autoradiographic estimation of the extent of reversible inactivation produced by microinjection of lidocaine and muscimol in the rat. Neurosci Lett 127:160-164.

McGaugh JL (1989) Dissociating learning and performance: drug and hormone enhancement of memory storage. Brain Res Bull 23:339-345.

McGaugh JL, Introini-Collison IB, Nagahara AH (1988) Memoryenhancing effects of posttraining naloxone: involvement of betanoradrenergic influences in the amygdaloid complex. Brain Res 446:37-49.

McGaugh JL, Cahill L, Roozendaal B (1996) Involvement of the amygdala in memory storage: interaction with other brain systems. Proc Natl Acad Sci USA 93:13508-13514.

McGaugh JL, Roozendaal B, Cahill L (1999) Modulation of memory storage by stress hormones and the amygdaloid complex. In: Cognitive neurosciences, Ed 2, pp 1081-1098. (Gazzaniga M, ed), Cambridge: MIT.

Muller J, Corodimas KP, Fridel Z, LeDoux JE (1997) Functional inactivation of the lateral and basal nuclei of the amygdala by muscimol infusion prevents fear conditioning to an explicit conditioned stimulus and to contextual stimuli. Behav Neurosci 111:683-691.

Packard MG, Introini-Collison I, McGaugh JL (1996) Stria terminalis lesions attenuate memory enhancement produced by intracaudate nucleus injections of oxotremorine. Neurobiol Learn Mem 65:278-282.

Parent MB, McGaugh JL (1994) Posttraining infusion of lidocaine into the amygdala basolateral complex impairs retention of inhibitory avoidance training. Brain Res 661:97-103.

Parent MB, Avila E, McGaugh JL (1995) Footshock facilitates the expression of aversively motivated memory in rats given post-training amygdala basolateral complex lesions. Brain Res 676:235-244.

Paxinos G, Watson C (1997) The rat brain in stereotaxic coordinates. San Diego: Academic.
Power AE, Roozendaal B, McGaugh JL (1998) The memory-enhancing effects of systemic glucocorticoids require muscarinic cholinergic activation in the basolateral amygdala. McGaugh Festschrift Abstr 10.

Quirarte GL, Roozendaal B, McGaugh JL (1997) Glucocorticoid enhancement of memory storage involves noradrenergic activation in the basolateral amygdala. Proc Natl Acad Sci USA 94:14048-14053.

Roozendaal B, McGaugh JL (1996) Amygdaloid nuclei lesions differentially affect glucocorticoid-induced memory enhancement in an inhibitory avoidance task. Neurobiol Learn Mem 65:1-8.

Roozendaal B, McGaugh JL (1997a) Basolateral amygdala lesions block the memory-enhancing effect of glucocorticoid administration in the dorsal hippocampus of rats. Eur J Neurosci 9:76-83.

Roozendaal B, McGaugh JL (1997b) Glucocorticoid receptor agonist and antagonist administration into the basolateral but not central amygdala modulates memory storage. Neurobiol Learn Mem 67:176-179.

Roozendaal B, Portillo-Marquez G, McGaugh JL (1996) Basolateral amygdala lesions block glucocorticoid-induced modulation of memory for spatial learning. Behav Neurosci 110:1074-1083.

Salinas JA, Introini-Collison IB, Dalmaz C, McGaugh JL (1997) Posttraining intraamygdala infusions of oxotremorine and propranolol modulate storage of memory for reductions in reward magnitude. Neurobiol Learn Mem 68:51-59.

Schroeder JP, Packard MG (1998) Amygdala modulation of appetitively motivated hippocampal-dependent memory. Soc Neurosci Abstr $24: 755.8$.

Tomaz C, Dickinson-Anson H, McGaugh JL (1992) Basolateral amygdala lesions block diazepam-induced anterograde amnesia in an inhibitory avoidance task. Proc Natl Acad Sci USA 89:3615-3619.

Vazdarjanova A, McGaugh JL (1998) Basolateral amygdala is not critical for cognitive memory of contextual fear conditioning. Proc Natl Acad Sci USA 95:15003-15007.

Washburn MS, Moises HC (1992) Muscarinic responses of rat basolateral amygdaloid neurons recorded in vitro. $\mathrm{J}$ Physiol (Lond) 449:121-154.

Welsh JP, Harvey JA (1991) Pavlovian conditioning in the rabbit during inactivation of the interpositus nucleus. J Physiol (Lond) 444:459-480.

Womble MD, Moises HC (1992) Muscarinic inhibition of M-current and a potassium leak conductance in neurones of the rat basolateral amygdala. J Physiol (Lond) 457:93-114.

Womble MD, Moises HC (1993) Muscarinic modulation of conductances underlying the afterhyperpolarization in neurons of the rat basolateral amygdala. Brain Res 621:87-96. 